\title{
The effect of octreotide on gastric emptying at a dosage used to prevent complications after pancreatic surgery: a randomised, placebo controlled study in volunteers
}

\author{
M I van Berge Henegouwen, Th M van Gulik, L M A Akkermans, J B M J Jansen, \\ D J Gouma
}

Department of Surgery, Academic Medical Centre, University of Amsterdam M I van Berge Henegouwen Th $M$ van Gulik D J Gouma

Department of Surgery, University Hospital, Utrecht L M A Akkermans

Department of Gastroenterology, Academic Hospital, Nijmegen, The Netherlands

J B M J Jansen

Correspondence to: Dr M I van Berge Henegouwen, Department of Surgery, Academic Medical Centre, Meibergdreef 9, 1105 AZ Amsterdam, The Netherlands.

Accepted for publication 16 July 1997

\begin{abstract}
Background-Octreotide is used in many centres to prevent complications after pancreatic surgery. Delayed gastric emptying is a another complication occurring in around $30 \%$ of patients after pancreatoduodenectomy (PD) and causes prolonged hospital stay. The influence of octreotide on this complication is doubtful.

Aims-To assess the effect of octreotide, at the clinical dosage used after pancreatic surgery, on gastric emptying in healthy volunteers.

Subjects and methods-Eight healthy male volunteers (mean age 22.5 years) participated in this double blind, placebo controlled study. On day 1 subjects received $100 \mu \mathrm{g}$ of octreotide or placebo subcutaneously, three times daily and on day 2 , one hour after the fourth injection, gastric emptying, postprandial cholecystokinin (CCK) release, and mouth to caecum transit time (MCTT) were measured. This protocol was repeated after one week, in a crossover design. On the test day subjects received a liquid test meal $(1.57 \mathrm{MJ} / 300$ ml) and gastric emptying measurements were performed with applied potential tomography, a non-invasive, validated technique which measures gastric emptying through impedance differences. From the gastric emptying curves, lag time, $t_{50}$, and postlag emptying rate were measured. MCTT was measured using the hydrogen breath test.
\end{abstract}

Results-Lag time decreased from 29.6 (6.3) (mean (SEM)) to 12.2 (4.6) minutes $(p<0.05)$ during octreotide treatment; $t_{50}$ decreased from 87.8 (12.0) to $47.5(8.2)$ minutes $(p<0.02)$ and there was a trend towards an increased postlag emptying rate $(0.8$ to $1.6 \%$ per minute; $p=0.07)$. MCTT increased from 150 (12.7) to 229 (17.9) minutes during octreotide treatment $(p<0.01)$. Octreotide suppressed postprandial CCK release $(p<0.05)$.

Conclusions-MCTT was delayed by octreotide, suggesting impairment of small bowel transit. Octreotide administered at the clinical dosage for pancreatic surgery accelerates gastric emptying, mainly by shortening the lag time. Suppression of postprandial CCK release may be involved in this process. Octreotide administration is therefore not a contributing factor in the pathogenesis of delayed postoperative gastric emptying after PD and might even play a role in preventing this complication.

(Gut 1997; 41: 758-762)

Keywords: octreotide; gastric emptying; cholecystokinin; intestinal transit; pancreatic surgery

The most serious postoperative complication of pancreatic surgery is anastomotic leakage at the pancreatic remnant. This complication is reported in the literature in $9-19 \%$ of patients $^{1-7}$ and is associated with concomitant morbidity, prolonged hospital stay, and a mortality of $8-26 \% .^{5-7}$ A number of recent randomised, placebo controlled multicentre trials showed that octreotide could reduce postoperative complications when administered to patients undergoing pancreatic surgery. ${ }^{8-11} \mathrm{Al}-$ though mortality was not affected in these studies, perioperative treatment with octreotide seems to be indicated in pancreatic surgery. $^{8-11}$

Octreotide (SMS 201-995, Sandostatin) is a long lasting somatostatin analogue with an elimination half life of approximately 1.5 hours. $^{1213}$ Octreotide inhibits secretion of gastrointestinal hormones such as cholecystokinin (CCK), gastrin, pancreatic polypeptide, motilin, secretin, glucose dependent insulinotropic peptide (GIP), vasoactive intestinal polypeptide (VIP), insulin, and glucagon, and impairs gastric and pancreatic secretion and gall bladder motility. ${ }^{12-15}$

The effect of octreotide on gastric motility and emptying rate in patients after pancreatic surgery is unknown. Delayed gastric emptying is a complication occurring in $8-36 \%$ of patients after pancreatoduodenectomy. ${ }^{1-5} \mathrm{~A}$ number of factors may play a role in the pathogenesis of delayed gastric emptying: ischemia or oedema of the pylorus, ${ }^{16}$ intra-abdominal infectious complications, ${ }^{17}{ }^{18}$ resection of the duodenum which is the production site of most gastrointestinal hormones, ${ }^{19} 20$ and interruption of gastrointestinal neural connections by resection of the duodenum. ${ }^{20}{ }^{21}$ Perioperative administration of prokinetic agents might reduce the duration of this complication. 
Octreotide is reported to accelerate gastric emptying in healthy volunteers, especially the first phase of gastric emptying; the effects of octreotide on gastric motility are known to be dose dependent. ${ }^{22-24}$ Other actions on gastrointestinal motility are the inhibition of antral motility, the induction of phase III like activity of the migrating motor complexes in the interdigestive state, and prolongation of the mouth to caecum transit time (MCTT). ${ }^{22232526}$ These studies, which addressed the effect of octreotide on gastric emptying, tested the effect of a single low dose $(50 \mu \mathrm{g})$ subcutaneously, or oral doses of octreotide. ${ }^{22}{ }^{23}$ In an experimental study of the effect of octreotide on postoperative ileus in dogs, Cullen et al found a delay in gastric emptying for a dosage scheme of 0.83 $\mu \mathrm{g} / \mathrm{kg} / \mathrm{h}$ in continuous subcutaneous infusion. ${ }^{27}$ The effect of the dosage used prophylactically after pancreatic surgery $(100 \mu \mathrm{g}$, three times daily subcutaneously) on gastric emptying has not been assessed.

In this study we evaluated the influence of octreotide at a dosage used clinically after pancreatic surgery, on gastric emptying, MCTT, postprandial gastrointestinal hormone response, and adverse effects in healthy volunteers.

\section{Subjects and Methods}

Eight healthy male volunteers with a mean age of 23 years (range 19-27 years) and mean body weight of $78.4 \mathrm{~kg}$ (range 69-91 kg) gave their written informed consent to the study, which was approved by the Medical Ethics Committee of the Academic Medical Centre. Only male subjects were studied since the menstrual cycle influences gastric emptying in women. ${ }^{28-32}$ None of the volunteers had undergone abdominal surgery and none used drugs that might influence gastrointestinal motility. The subjects were not allowed to smoke during the test day or the preceding day.

Figure 1 shows the design of this placebo controlled, double blind, randomised study. All subjects were tested on two occasions, at which they received either octreotide or placebo in a crossover design. These test days were one week apart, to allow a washout period for octreotide. On day 1, subjects received either the clinical dose of octreotide (Sandostatin, Novartis Pharma BV, Arnhem, The Netherlands), $100 \mu \mathrm{g}$ three times daily, or an equal volume of placebo (sodium chloride) subcutaneously. Subjects and observers were blinded for placebo and octreotide injections. The next

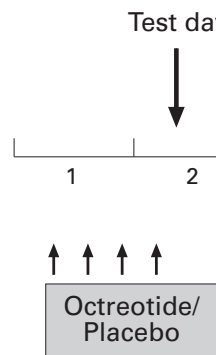

Test day

Figure 1: Study protocol, with octreotide and placebo injections indicated by the small black arrows. On the test day gastric emptying, CCK, and MCTT measurements were performed. day, one hour after the fourth injection, patients received a test meal (at $\mathrm{t}=0$ ) and measurements of gastric emptying and MCTT were carried out (from $\mathrm{t}=-15$ to $\mathrm{t}=300$ minutes). Blood samples were simultaneously collected for CCK measurements $(t=-15$ to $\mathrm{t}=180$ minutes).

TEST MEAL

To assess gastric emptying a standard liquid test meal was used, which consisted of $300 \mathrm{ml}$ of tomato juice, containing $40 \mathrm{~g}$ carbohydrate, $13 \mathrm{~g}$ protein, and $18 \mathrm{~g}$ fat; the total caloric weight was $375 \mathrm{kcal}(1.57 \mathrm{MJ})$. Lactulose (Lactulosum, Centrafarm BV, Etten-Leur, The Netherlands; $25 \mathrm{ml}, 16.8 \mathrm{~g}$ lactulose) was added for the hydrogen breath test and $4.5 \mathrm{~g}$ of broth powder was added to enable gastric emptying measurements by means of applied potential tomography; broth powder has a high ion density, which is used to lower the impedance.

\section{GASTRIC EMPTYING MEASUREMENTS}

The gastric emptying rate was measured by applied potential tomography (APT). This is a validated, non-invasive technique which measures gastric emptying through impedance differences. This technique has been described by others ${ }^{33}{ }^{34}$ and previously utilised in our department. ${ }^{35}$ In short, APT registers resistivity of the stomach and its contents through 16 electrodes that are placed around the upper abdomen at the level of the eighth costal cartilage, which corresponds to the gastric fundus or body. ${ }^{34}$ The electrodes are connected to a data collection system which emits and records electrical potentials. Sequential currents of $1 \mathrm{~mA}$ are sent through adjacent electrode pairs at $50 \mathrm{~Hz}$. During testing, impedance measurements are made at one minute intervals for two hours. These measurements are then computed as relative values of the preprandial data and a curve is constructed, corresponding to the gastric contents.

In order to obtain impedance differences between the gastric contents and surrounding tissue, the test meal contained $4.5 \mathrm{~g}$ of broth powder ("bouillon soup"), which shows up in the tomographic image produced by the APT equipment, because of its increased conductivity. This technique has been shown to correlate well with scintigraphic measurements. ${ }^{33}{ }^{34}$ To avoid interference of gastric acid with the test results, acid secretion was inhibited by $800 \mathrm{mg}$ of cimetidine (Tagamet) administered $90 \mathrm{~min}-$ utes before gastric emptying measurements. Cimetidine has no effect on gastric emptying, and in this way differs from other histamine $\mathrm{H}_{2}$ receptor blockers, such as ranitidine. ${ }^{36} 37$

The gastric emptying curves were analysed by three independent observers, unaware of the type of injection. Each observer estimated lag time, $\mathrm{t}_{50}$, and postlag emptying rate by drawing a horizontal line through the lag phase and a second line through the emptying curve, which was linear in all volunteers. Lag phase was defined as the time period from the end of the meal until the crossing of the two lines, which corresponded to a maximum of $5 \%$ emptying 


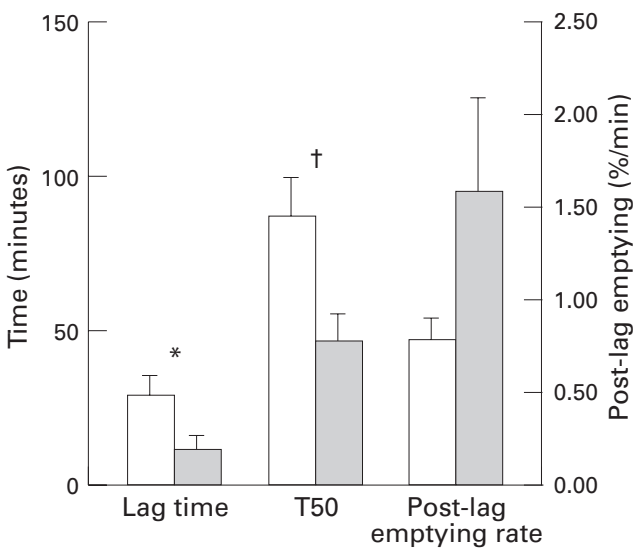

Figure 2: Lag time, $t_{50}$, and postlag emptying rate for placebo and octreotide treatment. ${ }^{*} p<0.05,+p<0.02$. Postlag emptying rate was not significantly different between placebo and octreotide treatment $(p=0.07)$. White columns, placebo; shaded columns, octreotide.

of the test meal from the gastric lumen. After this time period postlag emptying commenced. The final result was obtained by calculating the mean value for the three observers. The duration of the lag phase, the $t_{50}$ (time interval required for $50 \%$ emptying), and the rate of postlag gastric emptying were compared.

MCTT

MCTT was measured by means of the hydrogen breath test. Lactulose (16.8 g) was added to the test meal; end expiratory volumes of 30 $\mathrm{ml}$ were collected every 10 minutes for 300 minutes and hydrogen concentrations were measured using a lactometer $\mathrm{H}_{2}$ breath tester (Lactoscreen). MCTT was defined as the time to an increase above $10 \mathrm{ppm}$ compared with baseline values during at least two consecutive readings.

HORMONE ASSAYS

Blood samples were taken in the fasting state, at -15 and 0 minutes, and, after consumption of the test meal, every 15 minutes for 90 minutes and subsequently at 120 and 180 minutes. Blood was collected in ice chilled tubes and plasma was stored at $-30^{\circ} \mathrm{C}$ until analysis. CCK plasma concentrations were measured by a sensitive and specific radioimmunoassay as described previously. ${ }^{38}$ Indices of CCK release were basal concentration (mean concentrations at -15 and 0 minutes) and maximum increase (pmol/l).

\section{SYMPTOMS}

Symptoms that occurred during placebo/ octreotide treatment were scored by means of a questionnaire after both experimental treatments. Scoring was performed on the morning before the test meal was administered. Subjects could indicate the occurrence of the following symptoms: diarrhoea, defined as an increase in frequency of defecation to at least five times per day with watery stools; abdominal pain or tenderness, defined as pain or tenderness, at or after one or more of the injections; meteroism, defined as abdominal bloating or an incidence of flatus of over four times per day; nausea, defined as discomfort as reported by the subject, at or after one or more of the injections; or pain or tenderness at the injection site indicated during or within 30 minutes after subcutaneous injection.

\section{STATISTICAL ANALYSIS}

Lag time, $t_{50}$, postlag emptying rate, and MCTT measurements were recorded as mean, standard error of the mean (SEM), and range. Wilcoxon matched pairs test was used for statistical analysis of lag time, $\mathrm{t}_{50}$, postlag emptying rate, and MCTT. CCK concentrations were recorded as mean (SEM). For comparison of CCK concentrations, analysis of variance for repeated measures was used. CCK increase compared with basal concentrations was assessed using the Mann-Whitney U test. A p value of less than 0.05 was regarded as significant.

\section{Results}

GASTRIC EMPTYING AND MCTT MEASUREMENTS

The lag phase was shorter in octreotide treated subjects (12.2 (4.6) minutes (range 3.3-34.3) versus 29.6 (6.3) minutes (range 12.3-47.2); $\mathrm{p}<0.05)$. The $\mathrm{t}_{50}$ was accelerated by octreotide (47.5 (8.2) minutes (range 14.2-84.4) versus 87.8 (12.0) minutes (range 34.7-136.5); $\mathrm{p}<0.01)$. The postlag gastric emptying rate, measured as percentage emptying per minute, was higher for subjects given octreotide, although this did not reach statistical significance (1.6 (0.5) per cent per minute (range $0.4-4.7)$ versus $0.8(0.12)$ per cent per minute (range $0.4-1.3) ; \mathrm{p}=0.07$; fig 2). MCTT was significantly delayed during octreotide treatment (229 (17.9) (range 180-250) minutes versus 150 (12.7) (range 100-210) minutes; $\mathrm{p}<0.01)$.

\section{CCK RELEASE}

Basal CCK was $3.5(0.2) \mathrm{pmol} / 1$ in the placebo group and $3.2(0.1) \mathrm{pmol} / \mathrm{l}$ in the octreotide treated group. There was a maximum increase of $0.9(0.3) \mathrm{pmol} / 1$ in the placebo group compared with basal concentrations $(p<0.05)$ and a maximum increase of $0.2(0.1) \mathrm{pmol} / 1$ in the octreotide treated group (not significant compared with basal concentration). CCK concentrations were lower in subjects who received octreotide compared with those who received placebo, throughout the postprandial phase ( $\mathrm{p}<0.05$; fig 3$)$.

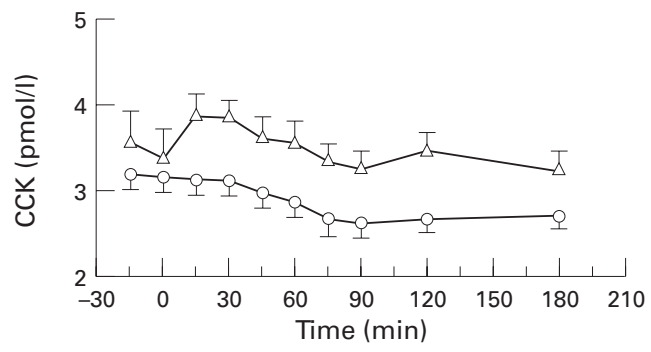

Figure 3: Postprandial CCK response for placebo and octreotide administration $(p<0.05)$. There was a significant postprandial CCK increase compared with basal levels in placebo treated subjects $(p<0.05)$. There was no significant postprandial CCK increase in octreotide treated subjects. Open triangles, placebo; open circles, octreotide 
TABLE 1 Symptoms during octreotide and placebo administration

\begin{tabular}{lll}
\hline Symptom & $\begin{array}{l}\text { Placebo } \\
(n=8)\end{array}$ & $\begin{array}{l}\text { Octreotide } \\
(n=8)\end{array}$ \\
\hline Diarrhoea & 0 & 7 \\
Abdominal pain & 0 & 4 \\
Meteroism & 0 & 3 \\
Nausea & 1 & 3 \\
Pain/tenderness at injection site & 0 & 1 \\
None & 7 & 1 \\
\hline
\end{tabular}

SYMPTOMS

Table 1 presents symptoms experienced by the subjects during octreotide and placebo administration. After placebo injection seven of the subjects were symptom free, whereas seven of the subjects experienced symptoms after octreotide injection.

\section{Discussion}

The influence of octreotide on gastric emptying after pancreatic surgery is unknown. In this study we found that octreotide, in a clinically used dosage (100 $\mu \mathrm{g}$ three times daily), accelerates gastric emptying in healthy volunteers. The increase in gastric emptying was partly caused by a shorter lag phase. These results are in accordance with previous studies, which used either oral SMS products, or lower, single subcutaneous dosage administrations. ${ }^{22}{ }^{23}$ Our results suggest that a delay in gastric emptying, as reported for a continuous subcutaneous octreotide infusion rate of 0.83 $\mu \mathrm{g} / \mathrm{kg} / \mathrm{h}$ in dogs ${ }^{27}$ which corresponds to a dose of approximately $500 \mu \mathrm{g}$ three times daily in humans, is not induced by dosages administered after pancreatic surgery $(100 \mu \mathrm{g}$ three times daily).

Because gastric emptying rate after octreotide treatment was accelerated, small bowel transit time was delayed much more than the 80 minute difference of total mouth to caecum transit time. To obtain an indication of small bowel transit time, gastric emptying time should be deducted from the total mouth to caecum transit time. These results concur with previous studies in which delayed small intestinal passage was found after octreotide administration. ${ }^{22} 233940$

Intraluminal fats cause decreased antral motility and increased phasic and tonic pyloric contractions in healthy volunteers. ${ }^{41}{ }^{42}$ This delay in gastric emptying is partly mediated through CCK release. Intestinal fat causes CCK release $^{43}$ and CCK inhibits gastric emptying of liquid and solid meals in a dose dependent manner. ${ }^{44-46}$ In healthy volunteers, intravenously administered CCK resulted in suppression of antral and duodenal contractions and increased tonic and phasic pyloric contractions. ${ }^{47}$ Octreotide inhibits postprandial and basal gastrointestinal hormone release, ${ }^{15} 48$ and in the present study, octreotide suppressed postprandial CCK release. By diminishing the postprandial CCK release, an element of the neurohumoral feedback mechanism of the antropyloroduodenal region is suppressed by octreotide. Therefore, diminished postprandial CCK release could be an important factor in the increased gastric emptying rate seen during octreotide treatment. The long lag phase for this liquid test meal is explained by its high fat and caloric content. During initial emptying of only a small part of the test meal (less than 5\%; lag phase) the fat containing nutrients trigger enterogastric feedback mechanisms-for example, the CCK response. Thus, the CCK response is evoked by the initial emptying of a meal from the stomach. A test meal containing enough fat (as in the test meal used in our study) evokes a significant CCK response, which prolongs the lag phase and delays the first gastric emptying phase. This also explains the fact that the CCK response occurs before the end of the lag phase.

The high incidence of diarrhoea in subjects treated with octreotide seems to be in contrast with the delay in intestinal transit found in these same subjects. Others have described diarrhoea as a result of octreotide administration. ${ }^{40}$ In that study, subjects also received octreotide at a dosage of $100 \mu \mathrm{g}$ three times daily and experienced watery diarrhoea, which declined after three days of octreotide administration. The decrease in pancreatic exocrine function by octreotide differed for the various enzymes: for chymotrypsin and trypsin the inhibitory actions of octreotide had ceased after seven days of octreotide administration, whereas for amylase, inhibition persisted. ${ }^{40}$ Apart from this diminished pancreatic exocrine function, octreotide inhibits glucose and amino acid absorption in the intestine. ${ }^{12}{ }^{49}$ This diminished intestinal nutrient absorption is the major cause of steatorrhoea in patients treated with octreotide. ${ }^{50}$

Apart from the impairment of small bowel transit and the inhibition of absorption of glucose, intraluminal amino acids, and fats, octreotide decreases fluid secretion in the jejunum and stimulates water and electrolyte absorption in the distal small bowel. ${ }^{12}{ }^{49}$ These combined actions do not seem to overrule the osmotic diarrhoea, as induced during octreotide treatment. This condition will not favour the process of nutrient absorption in the postoperative period after pancreatoduodenectomy. The delayed intestinal transit, as found in this study, does not seem to be an additional problem under these circumstances; in contrast, delay of passage time increases time for chyme-mucosa contact and might therefore improve gastrointestinal absorption.

In conclusion, octreotide at the dosage used prophylactically after pancreatic surgery, accelerates gastric emptying of a liquid meal. This is probably partly due to a suppression of postprandial CCK release. In the direct postoperative phase octreotide is therefore probably not a cause of delayed gastric emptying after pancreatoduodenectomy and might even play a role in preventing this complication. As this study was performed in healthy volunteers, further studies in patients after pancreatic surgery are indicated to assess the influence of octreotide on gastric emptying in this specific group of patients.

This study was partly supported by a grant from Novartis Pharma BV, Arnhem, The Netherlands. Some of the results of 
this study have been presented at a meeting of the Dutch Society for Gastroenterology in October 1996 and have been published in abstract form (Eur $\mathcal{f}$ Gastroenterol Hepatol 1996;8:A60).

1 Yeo CJ, Cameron JL, Maher MM, Sauter PK, Zahurak ML, Talamini MA, et al. A prospective randomized trial of pancreaticogastrostomy versus pancreaticojejunostomy after pancreaticoduodenectomy. Ann Surg 1995;222:580-8.

2 Zerbi A, Balzano G, Patuzzo R, Calori G, Braga M, Di Carlo V. Comparison between pylorus-preserving and Whipple pancreatoduodenectomy. Br F Surg 1995;82:975-9.

3 Cameron JL, Pitt HA, Yeo CJ, Lillemoe KD, Kaufman HS, Coleman J. One hundred and forty-five consecutive pancreaticoduodenectomies without mortality. Ann Surg 1993;217:430-5.

4 Klinkenbijl JH, van der Schelling GP, Hop WC, van Pel R, Bruining HA, Jeekel J. The advantages of pyloruspreserving pancreatoduodenectomy in malignant disease of preserving pancreatoduodenectomy in malignant disease of 216:142-5.

5 Miedema BW, Sarr MG, van Heerden JA, Nagorney DM, Mcllrath DC, Ilstrup D. Complications following pancreaticoduodenectomy. Current management. Arch Surg 1992; 127:945-9.

6 Trede M, Schwall G. The complications of pancreatectomy. Ann Surg 1988;207:39-47.

7 Braasch JW, Gray BN. Considerations that lower pancreatoduodenectomy mortality. Am f Surg 1977;133:480-4.

8 Buchler M, Friess H, Klempa I, Hermanek P, Sulkowski U, Becker $\mathrm{H}$, et al. Role of octreotide in the prevention of postoperative complications following pancreatic resection. Am F Surg 1992;163:125-30.

9 Pederzoli P, Bassi C, Falconi M, Camboni MG. Efficacy of octreotide in the prevention of complications of elective pancreatic surgery. Italian Study Group. Brf Surg 1994;81: 265-9.

10 Friess H, Beger HG, Sulkowski U, Becker H, Hofbauer B, Dennler HJ, et al. Randomized controlled multicentre study of the prevention of complications by octreotide in study of the prevention of complications by octreotide in
patients undergoing surgery for chronic pancreatitis. $B r f$ patients undergoing surg

11 Montorsi M, Zago M, Mosca F, Capussotti L, Zotti E, Ribotta G, et al. Efficacy of octreotide in the prevention of pancreatic fistula after elective pancreatic resections: a prospective, controlled, randomized clinical trial. Surgery 1995;117:26-31.

12 Harris AG. Somatostatin and somatostatin analogues: pharmacokinetics and pharmacodynamic effects. Gut 1994;35 S1-4.

13 Kutz K, Nuesch E, Rosenthaler J. Pharmacokinetics of SMS 201-995 in healthy subjects. Scand $\mathcal{F}$ Gastroenterol 1986; 119:65-72.

14 Gyr KE, Meier R. Pharmacodynamic effects of Sandostatin in the gastrointestinal tract. Digestion 1993;54(suppl 1): $14-9$.

15 Stolk MF, van Erpecum KJ, Koppeschaar HP, de Bruin Wl, Jansen JB, Lamers CB, et al. Postprandial gallbladder motility and hormone release during intermittent and continuous subcutaneous octreotide treatment in acromegaly. tinuous subcutaneous

16 Liberski SM, Koch KL, Atnip RG, Stern RM. Ischemic gastroparesis: resolution after revascularization. Gastroenterology 1990;99:252-7

17 Hunt DR, McLean R. Pylorus-preserving pancreatectomy: functional results. Br F Surg 1989;76:173-6.

18 Hocking MP, Harrison WD, Sninsky CA. Gastric dysrhythmias following pylorus-preserving pancreaticoduodenectomy. Possible mechanism for early delayed gastric emptying. Dig Dis Si 1990;35:1226-30.

19 Tanaka M, Sarr MG. Effects of exogenous motilin and morphine on interdigestive gastrointestinal motor activity after total duodenectomy in dogs. Surgery 1988;104:317-25.

20 Tanaka M, Sarr MG. Role of the duodenum in the control of canine gastrointestinal motility. Gastroenterology 1988; 94:622-9.

21 Tanaka M, Sarr MG. Total duodenectomy: effect on canine gastrointestinal motility. F Surg Res 1987;42:483-93.

22 Nelson-Piercy C, Hammond PJ, Gwilliam ME, KhandanNia N, Myers MJ, Ghatei MA, et al. Effect of a new oral somatostatin analog (SDZ CO 611) on gastric emptying, mouth to cecum transit time, and pancreatic and gut hormone release in normal male subjects. F Clin Endocrinol Metab 1994;78:329-36.

23 Fuessl HS, Carolan G, Williams G, Bloom SR. Effect of a long-acting somatostatin analogue (SMS 201-995) on postprandial gastric emptying of $99 \mathrm{mTc}$-tin colloid and mouth-to-caecum transit time in man. Digestion 1987;36 $101-7$.

24 von der Ohe MR, Camilleri M, Thomforde GM, Klee GG. Differential regional effects of octreotide on hum gastrointestinal motor function. Gut 1995;36:743-8.
25 Haruma K, Wiste JA, Camilleri M. Effect of octreotide on gastrointestinal pressure profiles in health and in functional and organic gastrointestinal disorders. Gut 1994;35:1064-9.

26 Vecht J, van der Kleij F, Lamers CBHW, Masclee AAM. Effect of octreotide on small intestinal motility and transit time in the fasting and the fed state [abstract]. Neth $\mathcal{F} \mathrm{Med}$ 1994;44:A33.

27 Cullen JJ, Eagon JC, Dozois EJ, Kelly KA. Treatment of acute postoperative ileus with octreotide. Am F Surg 1993; 165:113-9.

28 Wald A, Van Thiel DH, Hoechstetter L, Gavaler JS, Egler $\mathrm{KM}$, Verm R, et al. Gastrointestinal transit: the effect of the menstrual cycle. Gastroenterology 1981;80:1497-500.

29 Notivol R, Carrio 1, Cano L, Estorch M, Vilardell F. Gastric emptying of solid and liquid meals in healthy young subjects. Scand 7 Gastroenterol 1984;19:1107-13.

30 Horowitz M, Maddem GJ, Chatterton BE, Collins PJ, Petrucco OM, Seamark R, et al. The normal menstrual cycle has no effect on gastric emptying. Br F Obstet Gynaecol 1985;92:743-6.

31 Gill RC, Murphy PD, Hooper HR, Bowes KL, Kingma YJ. Effect of the menstrual cycle on gastric emptying. Digestion 1987;36:168-74.

32 Petring OU, Flachs $\mathrm{H}$. Inter- and intrasubject variability of gastric emptying in healthy volunteers measured by scintig-
raphy and paracetamol absorption. Br $\mathcal{F}$ Clin Pharmacol 1990;29:703-8.

33 Mangnall YF, Kerrigan DD, Johnson AG, Read NW. Applied potential tomography. Noninvasive method for measuring gastric emptying of a solid test meal. Dig Dis Sci measuring gastric

34 Avill R, Mangnall YF, Bird NC, Brown BH, Barber DC, Seagar AD, et al. Applied potential tomography. A new noninvasive technique for measuring gastric emptying. Gastroenterology 1987;92:1019-26.

35 Tjeerdsma HC, Smout AJ, Akkermans LM. Voluntary suppression of defecation delays gastric emptying. Dig Dis Sci 1993;38:832-6.

36 Mushambi MC, Trotter TN, Barker P, Rowbotham DJ. A comparison of gastric emptying rate after cimetidine and
ranitidine measured by applied potential tomography. $\mathrm{Br} \mathcal{F}$ Clin Pharmacol 1992;34:278-80.

37 Forrest JA, Fettes MR, McLoughlin GP, Heading RC. Effect of long-term cimetidine on gastric acid secretion, serum gastrin, and gastric emptying. Gut 1979;20:404-7.

38 Jansen JB, Lamers CB. Radioimmunoassay of cholecystokinin in human tissue and plasma. Clin Chim Acta 1983;131: 305-16.

39 Baxter AJ, Mangnall YF, Loj EH, Brown B, Barber DC, Johnson AG, et al. Evaluation of applied potential tomography as a new non-invasive gastric secretion test. Gut 1988;

40 Friess H, Bordihn K, Ebert M, Malfertheiner P, Kemmer T, Dennler HJ, et al. Inhibition of pancreatic secretion under long-term octreotide treatment in humans. Digestion 1994; 55(suppl 1);10-5.

41 Heddle R, Collins PJ, Dent J, Horowitz M, Read NW, Chatterton $\mathrm{B}$, et al. Motor mechanisms associated with slowing of the gastric emptying of a solid meal by an intraduode lipid infusion. $\mathcal{F}$ Gastroenterol Hepatol 1989;4:437-47.

42 Heddle R, Dent J, Read NW, Houghton LA, Toouli J, Horowitz $\mathrm{M}$, et al. Antropyloroduodenal motor responses to intraduodenal lipid infusion in healthy volunteers. $A m \mathcal{F}$ Physiol 1988;254:G671-9.

43 Walsch JH, Mayer EA. Gastrointestinal hormones. In: Sleisenger MH, Fordtran JS, eds. Gastrointestinal disease. Philadelphia: Saunders, 1993:18-38.

44 Konturek JW, Thor P, Maczka M, Stoll R, Domschke W, Konturek SJ. Role of cholecystokinin in the control of gastric emptying and secretory response to a fatty meal in nor-
mal subjects and duodenal ulcer patients. Scand $\mathcal{f}$ mal subjects and duodenal

45 Debas HT, Farooq O, Grossman MI. Inhibition of gastric emptying is a physiological action of cholecystokinin. Gastroenterology 1975;68:1211-7.

46 Kleibeuker JH, Beekhuis H, Jansen JB, Piers DA, Lamers CB. Cholecystokinin is a physiological hormonal mediator of fat-induced inhibition of gastric emptying in man. Eur $\mathcal{F}$ Clin Invest 1988;18:173-7.

47 Fraser R, Fone D, Horowitz M, Dent J. Cholecystokinin octapeptide stimulates phasic and tonic pyloric motility in healthy humans. Gut 1993;34:33-7.

48 Lembcke B, Creutzfeldt W, Schleser S, Ebert R, Shaw C, Koop I. Effect of the somatostatin analogue sandostatin (SMS 201-995) on gastrointestinal, pancreatic and biliary function and hormone release in normal men. Digestion 1987;36:108-24.

49 Reichlin S. Somatostatin. N Engl f Med 1983;309:1556-63. 50 Creutzfeldt W, Lembcke B, Folsch UR, Schleser S, Koop I. Effect of somatostatin analogue (SMS 201-995, Sandostatin) on pancreatic secretion in humans. Am f Med 1987;82: $49-54$. 